\title{
EFFECT OF VARIATION OF COMPRESSION RATIO AND INJECTION PRESSURE ON PERFORMANCE AND EMISSION CHARACTERISTICS OF CI ENGINE USING VARIOUS
} ALTERNATIVE FUELS: A REVIEW

\author{
Ankit Agarwal ${ }^{1}$, S. L. Soni², Dinesh Kumar Sharma ${ }^{3}$, Sandeep Kumar Bhaskar ${ }^{4}$ \\ ${ }^{1}$ M. Tech. Scholar, Department of Mechanical Engineering, MNIT Jaipur, Rajasthan, India \\ ${ }^{2}$ Professor, Department of Mechanical Engineering, MNIT Jaipur, Rajasthan, India \\ ${ }^{3}$ Lecturer, Department of Mechanical Engineering, SKIT Jaipur, Rajasthan, India \\ ${ }^{4}$ Lecturer, Department of Mechanical Engineering, SKIT Jaipur, Rajasthan, India
}

\begin{abstract}
Compression Ignition (CI) engines are widely used for transportation, agriculture, power generation and industrial applications. The conventional fuel for CI engine is petro diesel. Among the countries in the world, India is one of the largest consumers of petro diesel fuel. Indian economy is very much dependant on the consumption of petro diesel. Brake thermal efficiency, brake specific fuel consumption, emissions of $\mathrm{CO}, \mathrm{HC}, \mathrm{CO}_{2}, \mathrm{NOx}$ and smoke opacity are the major considerations with the performance and emission characteristics of CI engine. Injection pressure, compression ratio, injection timing, and fuel quality are parameters which affect the engine performance and emissions. For optimizing the consumption of diesel, use of blends of alternative fuels with diesel has been promoted and study of engine parameters with the use of these fuels have been presented by many researchers across the world.

In this review paper, effect of variation of compression ratio and injection pressure on the performance and emission characteristics of CI engine using different alternative fuels has been studied and compared with the diesel fuel. Alternative fuels under study were ethanol, methanol, Jatropha Methyl Ester, Mahua Methyl Ester and Pangomia Methyl Ester in $20 \%$ blending with diesel fuel. In this study, compression ratios 16.5, 17.5, 18.5 and injection pressures 200, 225, 250 bar have been considered for review. Review reveals that performance characteristics have been improved for all test fuels with increasing compression ratio and injection pressure at full load conditions. On the other hand emission characteristics of engines have been affected as $\mathrm{NO}_{x}$ increase and $\mathrm{HC}$ and $\mathrm{CO}$ decrease with increase in compression ratio and injection pressure for all test fuels.
\end{abstract}

Keywords: injection pressure; compression ratio; alternative fuels; emission.

\section{INTRODUCTION}

CI engines are widely used for transportation, automotive, agricultural applications, power generations and industrial applications because of their high fuel efficiencies and ease of operation. The existing CI engines conventional diesel fuel is derived from crude oil. As the natural resources are on the verge of depletion, therefore, alternative fuels derived from bio-origin are receiving much attention to overcome the various issues, such as, depletion of conventional fuel reserves, increased environmental pollution, increasing cost etc. [1][2].These issues have triggered several research studies to replace petroleum based diesel fuel with bio-fuels. The advantages of bio-origin fuels are their ease of availability, controlled production and lower toxicity as compared to the conventional diesel fuel. The examples of such bio-fuels are ethanol, methanol, straight vegetable oils (SVO), bio-diesels and bio-oil. These fuels are having physical and chemical properties comparable with the diesel fuel. Further, SVOs suffered from several drawbacks viz. high viscosity, lower calorific value, and higher flash, pour and cloud point. These difficulties were subsequently overcome by the production of alkyl esters of vegetable oils (Triglyricides) called as "Bio-diesel".

Exhaust gases emitted from CI engines contribute to the environmental pollution in the form of Hydrocarbons (HC), Carbon mono-oxide (CO), Carbon di-oxide $\left(\mathrm{CO}_{2}\right)$, Oxides of Nitrogen $\left(\mathrm{NO}_{\mathrm{x}}\right)$ and Oxides of Sulphur $\left(\mathrm{SO}_{\mathrm{x}}\right)$. CI engines also produce black smoke containing unburnt carbon particles. In addition to these, pollution regulatory bodies across the world are constantly has an eagle watch on the exhaust emissions from engines with the use of different fuels to fulfill requirements according to international emission standards. So, exhaust emissions control is also as important as improvement of performance of compression ignition engines. Recently, by changing the engine operating parameters such as valve timing, injection timing, and atomization ratio, studies have been carried out on the IC engines, aiming to reduce the emissions [3]. Out of these, compression ratios (CRs) and injection pressures (IPs) identified as major factors, which play a vital role in the performance and emission characteristics of CI engines. 
A review has been prepared to study the effect of compression ratio and injection pressure on the performance characteristics and emission characteristics of CI engine using various alternative fuels. Comparison of results of these alternative fuels has been made with those of diesel fuel. Data for review selected are from the results of various alternative fuels such as Methanol, Ethanol, Jatropha methyl ester, Mahua methyl ester, and Pongamia oil methyl ester. Whereas the values of CRs and IPs chosen are 16.5:1, 17.5:1, 18.5:1 and 200, 225, 250 bar respectively.

In selected CI engines for this study, the compression ratio is 16.5:1 and the pressure of fuel injection is 200 bar. If we take compression ratios higher than the original, the air intake in the cylinder is more compressed, resulting powerful explosion and better combustion of the fuel. If we inject the fuel at higher pressure, the atomization of the fuel improves. The droplets vaporize, taking the heat from the hot air and form a combustible mixture and starts burning. As the burning starts, the vaporization of fuel is accelerated as more heat is available. The degree of atomization is indicated by the fineness of fuel particles in the spray. The fuel particles velocity is the most important factor affecting the degree of atomization. As we increase the fuel velocity by increasing the injection pressure, degree of atomization is increased. As the degree of atomization increase, it burns rapidly. So the whole fuel is burnt properly and there is a reduction in emission [4].

Cenk Sayin et al. [3] investigated the effects of injection pressure on methanol blended diesel fuel at different loads and different injection timings. The results indicated that NOx emissions slightly increased; smoke opacity, CO and UHC emissions decreased drastically by methanol addition to the fuel blend; and $\mathrm{CO}_{2}$ emissions increased because of the improved combustion. By using methanol-blended diesel fuels, smoke opacity, $\mathrm{CO}$ and UHC emissions reduced by 5$22 \%, 33-52 \%$ and $26-50 \%$ respectively, while $\mathrm{CO}_{2}$ and $\mathrm{NO}_{\mathrm{x}}$ emissions increased by $14-68 \%$ and $22-69 \%$ respectively, depending on the engine running conditions. Increased amount of methanol in the fuel mixture produced higher peak temperature in the cylinder. This effect resulted in increased $\mathrm{NO}_{\mathrm{x}}$ emissions.

Kadir Uslu et al. [5] experimentally investigated the influence of injection pressure on the exhaust emissions of a diesel engine by using ethanol blended diesel fuel. The results indicated that $\mathrm{NO}_{\mathrm{x}}$ emissions slightly increased; $\mathrm{CO}$ and unburned $\mathrm{HC}$ emissions decreased drastically by ethanol addition; and $\mathrm{CO}_{2}$ emissions increased because of the improved combustion. By using ethanol blended diesel fuels, $\mathrm{CO}$ and unburned $\mathrm{HC}$ emissions reduced $10-70 \%$ and 10-45\%, while $\mathrm{CO}_{2}$ and $\mathrm{NO}_{\mathrm{x}}$ emissions increased 10-50\% and $5-15 \%$, respectively, depending on the engine running conditions. As the amount of ethanol increased in the fuel mixture, proper combustion happened and resulted in a higher peak temperature in the cylinder. As the peak temperature of cylinder increased, it resulted in the better formation of NOx.
S, Jindal et al. [2] demonstrated that using Jatropha Methyl ester as a fuel in CI engine with increase in compression ratio and injection pressure, the performance of the engine improved. He used this study with regard to the engine performance measured in terms of Brake Specific Fuel Consumption (BSFC) and Brake Thermal Efficiency (BTE). The highest performance is delivered by the engine at 250 bar injection pressure and compression ratio of 18.5 at which BSFC improves by $10 \%$ and BTE improves by $8.9 \%$ than that with diesel at full load condition. With regard to emission aspects, increase in compression ratio lead to increase in emission of $\mathrm{HC}$ and exhaust gas temperature, whereas Smoke and CO emission reduced. NOx emissions are found to remain unaffected at higher injection pressure as compared to diesel fuel.

Balaji Mohan et al. [6] experimented on Single Cylinder CI engine Genset, using B20 blend of Mahua methyl ester to meet Genset emission standards prevailing in India. By varying injection parameters like nozzle opening pressure and injection timing, the emissions were measured to check, whether these meet regulatory norms. Results stated that increasing injection pressure to 275 bar and retarding injection timing to $21^{\circ}$ BTDC, the BTE increases about $10 \%$ and $\mathrm{BSFC}$ reduces about $8 \%$ on full load compared to that with diesel fuel. Along with BTE and BSFC, $\mathrm{NO}_{\mathrm{x}}$ emission also increased by $6 \%$, which was accounted as adverse effect.

Metin Gumus et al. [1] experimentally investigated the effects of operating conditions such as compression ratio, and injection pressure on the engine performance and exhaust emissions of a Single Cylinder CI engine using Pangomia oil methyl ester blended with diesel fuel. Based on the results of this study, it was concluded that BSFC, BTE and Brake Specific Energy Consumption (BSEC) are considerably improved with the increase in CR compared to the original. For all CRs, the emissions of $\mathrm{HC}$, amount of Opacity (OP) and $\mathrm{CO}$ with biodiesel blends are lower than that of diesel fuel. With the increase in CR, the peak temperature was also high and less amount of opacity (OP), $\mathrm{CO}$ and $\mathrm{HC}$ emissions were exhausted from engine. But, this effect increased NOx emissions. The increased injection pressure gave the better results for BSFC, BSEC and BTE compared to that of original injection pressure. Finer fuel droplets obtained with increased IP provided more surface area and better mixing with air. This resulted in better combustion. OP, HC, and CO emissions decreased and NOx emissions increased with the increase in IP for the all test fuel blends. [7], [8], [9] also reported the effect of injection pressure on performance and emission characteristics of CI engine using SVO and its blends with diesel fuel.

Comparison of parameters of performance and emission characteristics has been made in \% change with respect to the diesel fuel at full load conditions. Results have been shown for the effect of CRs and IPs separately over the performance characteristics (BTE and BSFC) and emission characteristics ( $\mathrm{HC}, \mathrm{CO}$ and $\mathrm{NOx})$. 
2. EFFECT OF COMPRESSION RATIO ON ENGINE PERFORMANCE AND EMISSION CHARACTERISTICS

\subsection{Effect of CR on Brake Thermal Efficiency} (BTE)

As the CR got to be increased, the BTE of the engine got increased compared to original $\mathrm{CR}$ of engines. It happened due to proper burning of the fuel at CRs higher than original $\mathrm{CR}$. Figure 2.1presents percentage change in BTE for different alternative fuels with respect to diesel at higher CR at IP 200 bar.

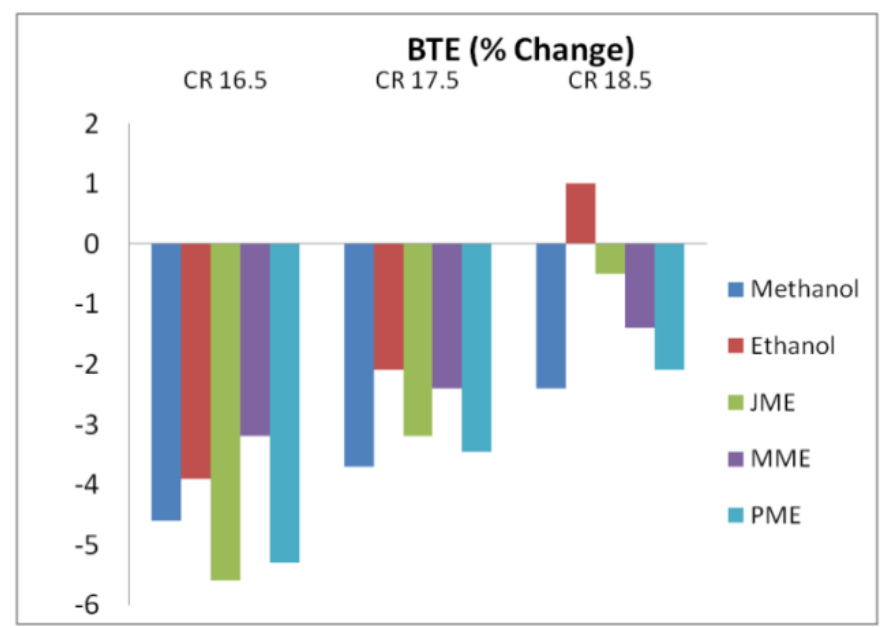

Fig 2.1: Effect of CR on BTE

\subsection{Effect of CR on Brake Specific Fuel}

\section{Consumption (BSFC)}

With higher CR, the BSFC of the engine is decreased due to better combustion of fuel. Figure 2.2 presents $\%$ change in BSFC for alternative fuels with respect to diesel at CRs higher than 16.5 at IP 200 bar.

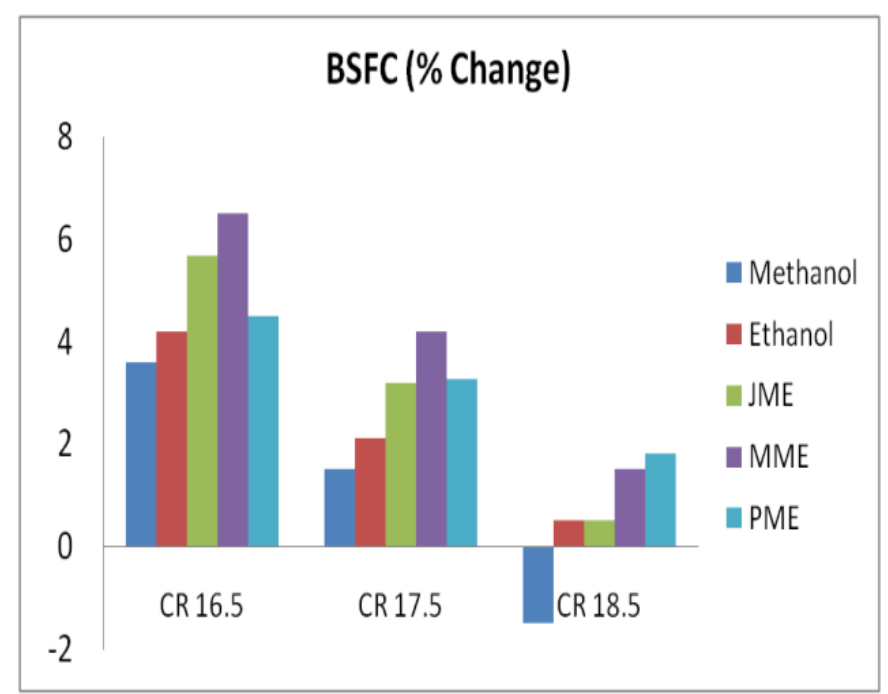

Fig 2.2: Effect of CR on BSFC

\subsection{Effect of CR on Nitrous Oxide Emission (NOx)}

Since on higher CRs fuel is properly burns that resulted in a higher peak temperature in engine cylinder and so the formation of nitrogen oxides got increased. Figure 2.3 presents \% change in NOx emission with alternative fuels with respect to diesel at CRs higher than 16.5 at IP 200 bar.

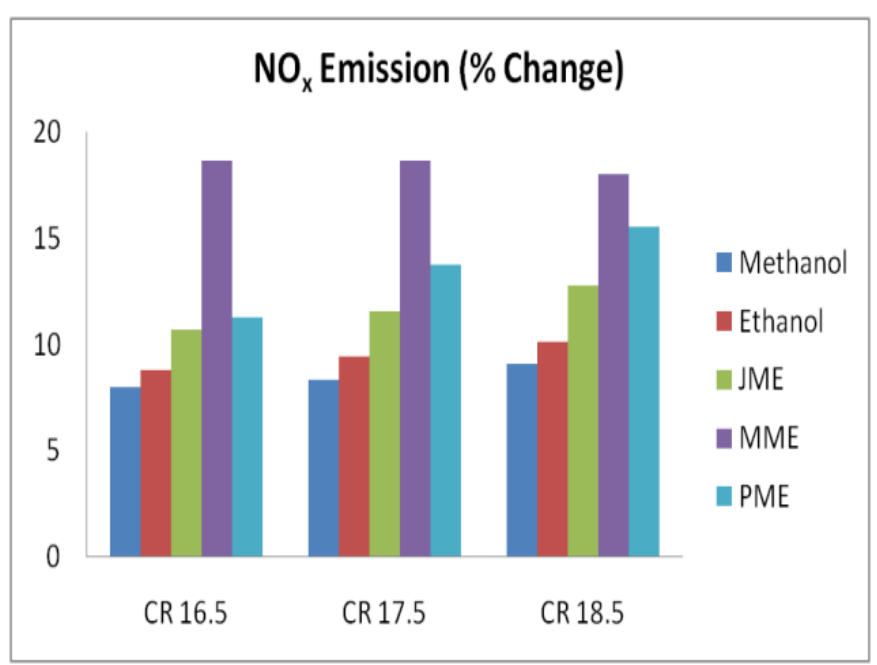

Fig 2.3: Effect of CR on NOx emission

\subsection{Effect of CR on Hydrocarbons (HC)}

Figure 2.4 presents \% change in $\mathrm{HC}$ emission with respect to that of with diesel fuel at CR 16.5. Due to proper combustion $\mathrm{HC}$ emission is got to be reduced with all CRs higher than original at IP 200 bar.

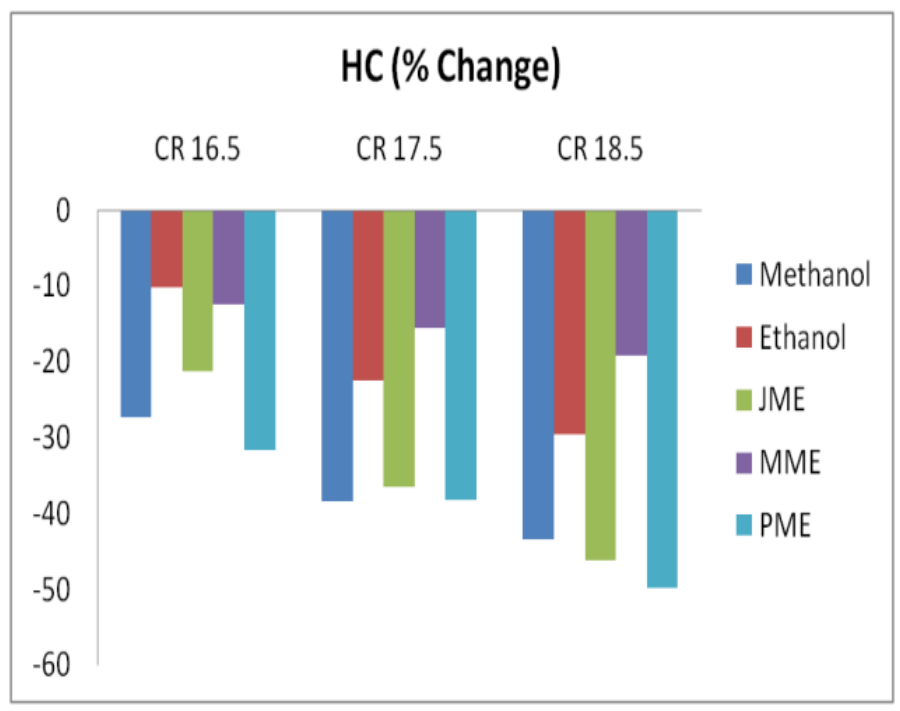

Fig 2.4: Effect of $\mathrm{CR}$ on $\mathrm{HC}$ emission

\subsection{Effect of CR on Carbon-Mono-oxide (CO)}

Similarly like HC emission CO generation rate is lower at the CRs higher than the original CR. Figure 2.5 presents \% change in $\mathrm{CO}$ concentration with respect to that of with diesel fuel at CR 16.5. IP is not being changed during this comparison. 


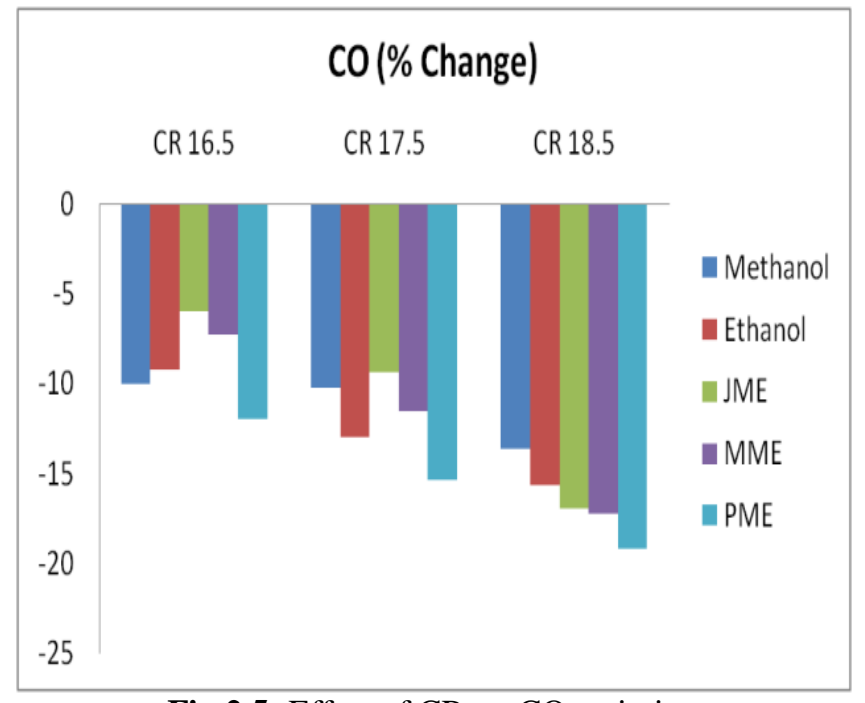

Fig 2.5: Effect of $\mathrm{CR}$ on $\mathrm{CO}$ emission

\section{EFFECT OF INJECTION PRESSURE ON} ENGINE PERFORMANCE AND EMISSION CHARACTERISTICS

\subsection{Effect of Injection Pressure (IP) on BTE}

Figure 3.1 shows comparison of BTE for various alternative fuels at various IPs higher than the original IP. When injection pressure is increased fuel droplets are properly atomized and these fine droplets properly mix with air. It is clear from the figure that BTE improves with higher IPs than the original.

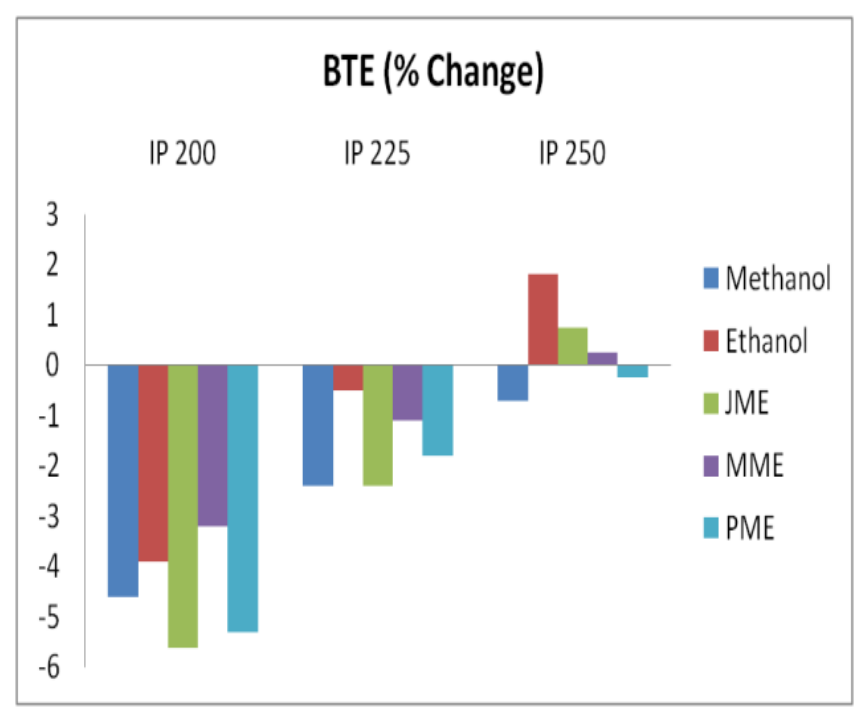

Fig 3.1: Effect of IP on BTE

\subsection{Effect of IP on BSFC}

Increase in IP, results into rapidly burning of fuels. So BSFC is decreased with IPs higher than the original. Figure 3.2 presents \% change in BSFC for various alternative fuels with respect to diesel at IP 200 bar for increased IPs at CR 16.5 .

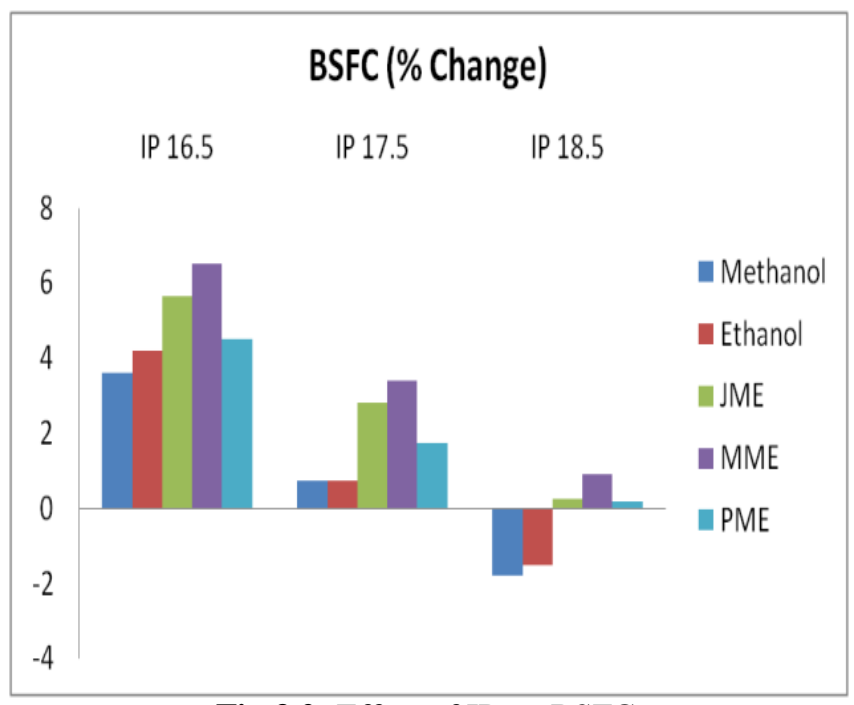

Fig 3.2: Effect of IP on BSFC

\subsection{Effect of IP on NOx}

As stated earlier, IP is got to be improved combustion so peak cylinder temperature is increased and therefore NOx emission increased compared to that of diesel fuel at IP 200 bar at CR 16.5. Figure 3.3 shows the effect of IPs on the NOx formation in engine with various alternative fuels.

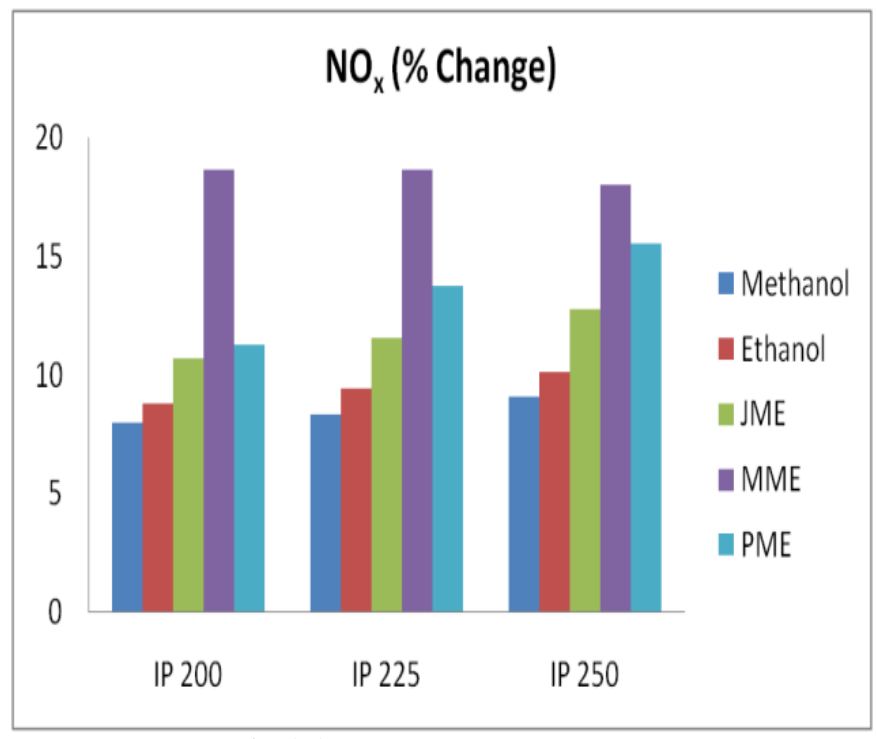

Fig 3.3: Effect of IP on NOx

\subsection{Effect of IP on HC}

Figure 3.4 presents \% change in $\mathrm{HC}$ emission with respect to that of diesel fuel at IP 200bar and CR 16.5. Increased IP resulted in better combustion and $\mathrm{HC}$ emission is observed to be lower than that of diesel fuel. As the IP is increased, fuel atomization happens efficiently. This results into proper burning of the fuel and formation of $\mathrm{HC}$ is reduced. Unburnt hydrocarbons formed in the engine indicate towards improper burning of fuel in engine. To improve combustion of fuel in engine, IPs is got to be increased so that fuels having higher density than the diesel could be atomized properly to prevent formation of $\mathrm{HC}$. 


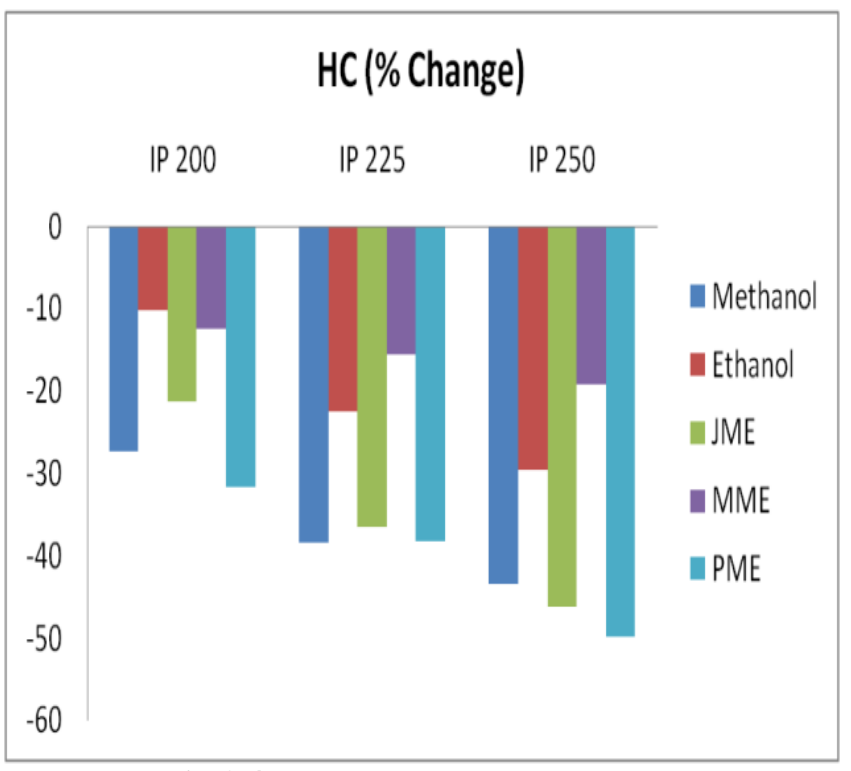

Fig 3.4: Effect of IP on HC emission

\subsection{Effect of IP on CO}

With increase in IP, the fuel atomization happens efficiently. This results proper burning of the fuel and production of carbon particles is reduced. Figure 3.5 presents $\%$ change in $\mathrm{CO}$ emission for different alternative fuels with respect to diesel for increased IPs at CR 16.5

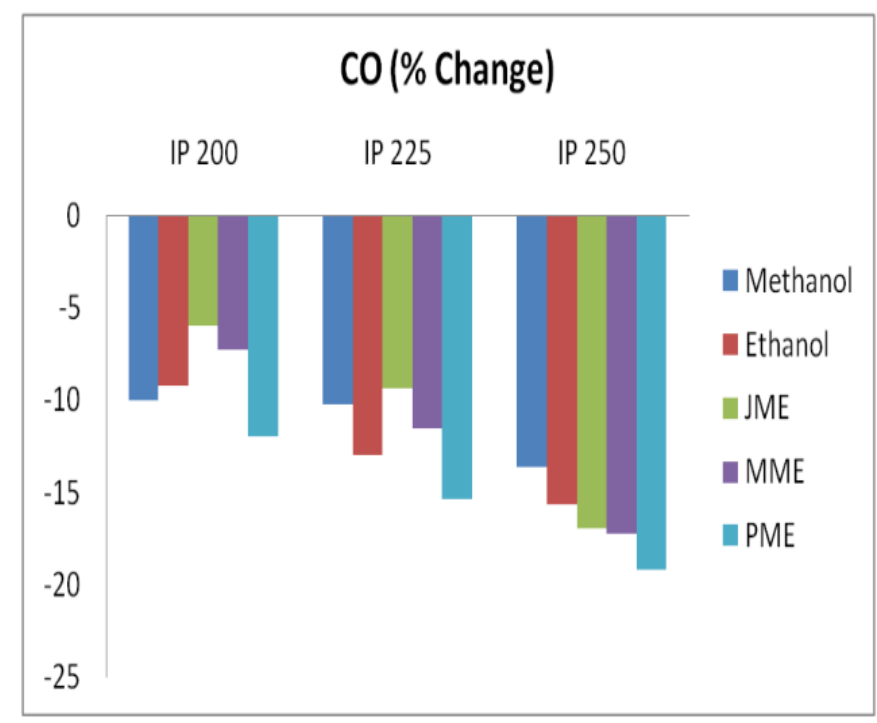

Fig 3.5: Effect of IP on CO

\section{CONCLUSION}

From this study, the effect of operating parameters viz. compression ratios and injection pressures on the engine performance and emission characteristics of CI engine using alternative fuels Methanol, Ethanol, Jatropha methyl ester, Mahua methyl ester, and Pongamia oil methyl ester was studied and compared. Based on the various effects, the conclusions are drawn as follows:

1. BTE and BSFC are considerably improved with increase in CR compared to the normal CR 16.5 at IP 200 bar. Increasing CR enhances density of air charge in cylinder. More air in the fuel spray contributes to the efficient and exhaustive combustion of the fuel. For all CRs, the emissions of $\mathrm{HC}$ and $\mathrm{CO}$ with biodiesels are lower than that of diesel fuel. With the increase in CR, the peak temperature is also high which results into higher $\mathrm{NO}_{\mathrm{x}}$ emissions.

2. The increased IPs gave better results of BTE and BSFC compared to the original IP. Finer fuel droplets formed due to increased IP that provided more surface area and better mixing with air and this effect improves combustion. Hence $\mathrm{HC}$, and $\mathrm{CO}$ emissions decreased and $\mathrm{NO}_{\mathrm{x}}$ emissions increased with the increase in IP for the all fuel blends.

3. If $\mathrm{CR}$ and IP increased further, more induced vibrations were observed in the engine along with knocking.

Yet optimized injection pressure and compression ratio are to be analyzed for different blending percentage of alternative fuels with diesel. Injection timing also plays an important role in minimization of knocking. The effects of injection timing on the knocking and combustion characteristics of CI engine yet to be optimized.

\section{REFERENCES}

[1] Agarwal, A. K., Dha, A., Gupta, J. G., Kim, W. I., \& Lee, C. S. (2014). Effect of fuel injection pressure and injection timing on spray characteristics and particulate size-number distribution in a biodiesel fuelled common rail direct injection diesel engine. Applied Energy , 130, 212-221.

[2] Domkundwar, V. M., \& Domkundwar, A. (2012). A Course in Internal Combustion Engines. Dhanpat Rai \& Co.

[3] Jindal, S., Nandwana, B., Rathore, N., \& Vashistha, V. (2010). Experimental investigation of the effect of compression ratio and injection pressure in a direct injection diesel engine running on Jatropha methyl ester. Applied Thermal Engineering , 30, 442-448.

[4] Mohan, B., Yang, W., Raman, V., alingam, V. S., \& Chou, S. K. (2014). Optimization of biodiesel fueled engine to meet emission standards through varying nozzle opening pressure and static injection timing. Applied Energy , 130, 450-457.

[5] Raeie, N., Emami, S., \& Sadaghiyani, O. K. (2014). Effects of injection timing before and after top dead center on the propulsion and power in a diesel engine. Propulsion and Power Research , 3 (2), 5967.

[6] Sayin, C., \& Gumus, M. (2011). Impact of compression ratio and injection parameters on the performance and emissions of a DI diesel engine fueled with biodiesel-blended diesel fuel. Applied Thermal Engineering, 31, 3182-3188.

[7] Sayin, C., Ilhan, M., Canakci, M., \& Gumus, M. (2009). Effect of injection timing on the exhaust 
emissions of a diesel engine using diesel-methanol blends. Renewable Energy (34), 1261-1269.

[8] Sayin, C., Uslu, K., \& Canakci, M. (2008). Influence of injection timing on the exhaust emissions of a dual-fuel CI engine. Renewable Energy , 33, 1314-1323.

[9] Suh, H. K. (2011). Investigations of multiple injection strategies for the improvement of combustion and exhaust emissions characteristics in a low compression ratio (CR) engine. Applied Energy , 88, 5013-5019.

\section{BIOGRAPHIES}

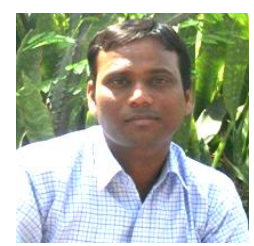

Mr. Ankit Agarwal is M. Tech. Scholar (Energy) from MNIT, Jaipur. His research areas are IC Engines, Alternative fuels, Heat Transfer, Refrigeration and Air-Conditioning etc.

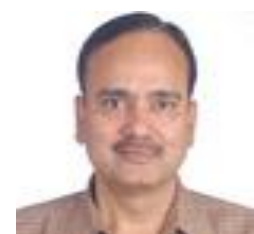

Dr. S. L. Soni is Professor of MNIT, Jaipur. He has published many papers in various International Journals of the field of IC Engines and Thermal Engineering.

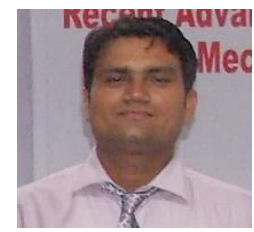

Mr. Dinesh K Sharma is Asst. Prof. in Swami Keshvanand Institute of Technology, Jaipur. He has presented and published many research papers in various National/International Journals.

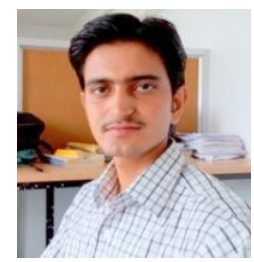

Mr. Sandeep K Bhaskar is Assistant Professor in Swami Keshvanand Institute of Technology, Jaipur. His research areas are IC Engines, Solar Energy, Wind Energy etc. 